\title{
Decoding Food Labels: Tools for People with Food Allergies $^{1}$
}

Amy H. Simonne and Elizabeth A. Gollub ${ }^{2}$

\section{Background}

True food allergies are immune-mediated systemic allergic reactions to certain foods. According to the Food and Drug Administration (FDA), true food allergies affect less than $2 \%$ of the adult population and 2-8\% of children. However, the impact of true allergies can be quite severe. Most childhood food allergies are found in young infants and children under 3 years old. Food allergies have a genetic component and may be more common among those with asthma.

Reactions to a food allergen can range from uncomfortable skin irritations to gastrointestinal distress to respiratory involvement to lifethreatening anaphylaxis-a systemic allergic reaction that generally involves several of these areas as well as the cardiovascular system. The number of people with food allergies appears to be increasing, especially among children. To keep pace with this trend, there is an increasing need for preemptive food selection strategies.

Currently, an individual with a food allergy must learn to read labels carefully and critically. This is because a food allergen may take on an unfamiliar name when used for processing purposes. For example, if eggs, one of the most allergenic foods, are used as a binder to retain water in a food product, the term binder, rather than egg, will appear on the food label.

Similarly, soy protein may be used for flavoring and listed on the label as natural flavoring.

The Food Allergen Labeling and Consumer Protection Act (FALCPA), which took effect on January 1, 2006, requires food manufacturers to use common names to identify major allergens. However, many consumers continue to have problems understanding complicated labeling information.

The goal of this publication is to provide information to help consumers understand ingredient statements on food packages so they can avoid foods and food products that might contain specific allergens. It also differentiates between allergies and intolerances, and discusses the potential for cross-contamination of foods both in and away from the home.

1. This document is FCS8781, one of a series of the Department of Family, Youth and Community Sciences, Florida Cooperative Extension Service, IFAS, University of Florida, Gainesville, FL 32611. First published: November 2004. Revised November 2007. Please visit the EDIS Web site at http://edis.ifas.ufl.edu

2. Amy Simonne, PhD, associate professor and extension specialist, and Elizabeth A. Gollub, PhD, MPH., RD., former OPS professional, Department of Family, Youth and Community Sciences, University of Florida, Gainesville, FL 32611. 


\section{Food Allergy vs. Food Intolerances vs. Histamine Sensitivity}

Most people experience an adverse reaction to some food at some point in their life. This does not necessarily mean that the individual is allergic to that food. Food intolerances, including sensitivity to elevated levels of histamine in foods, can produce a response similar to an allergic reaction. Adverse reactions and suspected allergens can be identified through a detailed history and specific allergy testing by a physician or qualified specialist (to exclude other causes).

The difference between food allergies and food intolerance is how the body handles the offending food. In the case of an allergy, the immune system recognizes a chemical in the food (usually a protein) as an allergen, and produces antibodies against it.

A response to an allergen may manifest as:

- Swelling of the lips

- Stomach cramps, vomiting, diarrhea

- Hives, rashes, eczema

- Wheezing or breathing problems

- Severely reduced blood pressure

Most common allergens are found in the following food groups:

1. Cow's milk (especially among children)

2. Wheat (especially among children)

3. Soy (especially among children)

4. Eggs

5. Peanuts

6. Tree nuts

7. Fish

8. Shellfish

9. Food additives (not true allergens, but capable of causing reaction or illness specific to a given person)
In most cases, children will outgrow their allergies to milk, wheat, soy, and eggs, but not to peanuts. Adults do not usually grow out of their allergies.

Food intolerance is more common than a true allergy and does not involve the immune system. Intolerance is a metabolic problem in which the body cannot adequately digest the offending food. This is usually because of a chemical deficiency (e.g., an enzyme deficiency).

An individual with food intolerance can generally consume a small amount of the offending food without experiencing symptoms. However, the specific amount may be different for each individual. Intolerances, unlike allergies, seem to intensify with age.

Histamine sensitivity may be considered a type of food intolerance. Because histamine is a primary mediator of an allergic response in the body, consumption of histamine can elicit a similar response. Histamine toxicity is most frequently associated with the consumption of spoiled fish, but has also been associated with aged cheeses and red wines. Elevated levels of histamine occur naturally in these foods. 


\section{Decoding Allergens in Foods}

\section{Eggs}

If you are allergic to egg protein, you should avoid any product with the word egg on the label. You should also avoid products with the following terms on their labels:

\begin{tabular}{|l|l|}
\hline Albumin & Lysozyme \\
\hline Binder & Ovalbumin \\
\hline Coagulant & Ovomucin \\
\hline Emulsifier & Ovomucoid \\
\hline Globulin/ovaglobulin & Ovovitellin \\
\hline Lecithin & Vitellin \\
\hline Livetin & Simplesse* \\
\hline \multirow{2}{*}{ Simplesse } \\
\hline
\end{tabular}

Types of foods that are likely to contain egg protein include:

\begin{tabular}{|l|l|}
\hline Baked goods and packaged mixes & Marshmallows \\
\hline Creamy fillings and sauces & Processed meat products \\
\hline Breakfast cereals & Pastas/egg noodles \\
\hline Malted drinks and mixes & Salad dressings/mayonnaise \\
\hline Pancakes and waffles & Soups \\
\hline Marzipan* & Meringue \\
\hline Custard & Pudding \\
\hline \multicolumn{2}{|l}{} \\
$*$ Marzipan might be made with egg whites \\
\hline
\end{tabular}

\section{Milk}

Milk and milk proteins are also found in a variety of processed foods. Individuals with milk protein allergies should avoid all types of milk, ice cream, yogurt and cheese, including vegetarian cheese. Allergic individuals should avoid foods with the terms butter, cream, casein, caseinate, whey, or emulsifier on the labels. Additional labeling terms indicating the presence of milk proteins in a food product include:

\begin{tabular}{|l|l|}
\hline Caramel color or flavoring & Lactose \\
\hline High protein flavor & Natural flavoring \\
\hline Lactalbumin/lactalbumin phosphate & Solids \\
\hline Lactoglobulin & Simplesse* \\
\hline & $*$ \\
& $*$ Simplesse
\end{tabular}


Types of foods that are likely to contain milk protein include:

\begin{tabular}{|l|l|}
\hline Battered foods & Custard, puddings, sherbet \\
\hline Baked goods and mixes & Imitation sour cream \\
\hline Breakfast cereals & Instant mashed potatoes \\
\hline Chocolate & Margarine \\
\hline Cream sauces, soups and mixes & Sausages \\
\hline Gravies and mixes & Sweets/candies \\
\hline Ghee* & \\
\hline \multirow{2}{*}{$*$} \\
$*$
\end{tabular}

\section{Wheat}

Individuals who are allergic to wheat proteins should avoid any product that contains the term wheat, bulgur, couscous, bran, gluten, bread crumbs, or hydrolyzed wheat proteins on the label. Wheat has binding properties that are very useful in the food processing industry, and this has extended to use in the pharmaceutical industry. Individuals with wheat allergies should discuss the composition of prescription or over-the-counter medications with a pharmacist prior to use. Rye and barley also contain gluten and must be avoided. The presence of wheat protein in a food product may be indicated by the following label terms:

\begin{tabular}{|l|l|}
\hline $\begin{array}{l}\text { Flour - bleached, unbleached, white, whole } \\
\text { wheat, all-purpose, enriched, graham, } \\
\text { durum, high gluten, high protein }\end{array}$ & MSG (monosodium glutamate) \\
\hline Cornstarch & Vegetable starch/gum \\
\hline Farina & Gelatinized starch \\
\hline Semolina & Spelt* \\
\hline Hydrolyzed vegetable protein & Kamut* \\
\hline Modified food starch & Triticale* \\
\hline Miso** & Malt \\
\hline \multicolumn{2}{|l}{$* \begin{array}{l}\text { *Spelt and kamut are both relatives of wheat; triticale is a wheat/rye hybrid. These } \\
\text { grains are gaining popularity as wheat substitutes. Spelt-, kamut-, and triticale- } \\
\text { containing products are marketed primarily through health/natural food stores. } \\
* * \text { Fermented soy product with up to 50\% wheat }\end{array}$} \\
\hline
\end{tabular}

Types of foods that are likely to contain wheat proteins include:

\begin{tabular}{|l|l|}
\hline Ale/beer/wine/bourbon/whiskey & Gravy \\
\hline $\begin{array}{l}\text { Baked goods and mixes - including barley } \\
\text { products }\end{array}$ & Ice cream and cones \\
\hline Battered or breaded foods & Malts and flavorings \\
\hline Breakfast cereals & Pasta/egg noodles \\
\hline Candy/chocolate & Soup and soup mixes \\
\hline Processed meats & Soy sauce \\
\hline Coffee substitutes & Pretzels, chips, crackers \\
\hline
\end{tabular}




\section{Soy}

Soy can be consumed as a whole bean, a nut, or a cow-milk alternative. Soy can be processed into foods such as tofu, soy curd, yuba (soy film), and soy flour. Soy can be fermented into products such as tempeh, natto, miso, and soy sauce. Soy has a variety of supportive uses in the food industry as well. It can be a thickener, stabilizer, emulsifier, and a protein extender. Allergic individuals should avoid products with these terms on the label, in addition to products containing the terms soy and soybean.

Soybean oil should be protein-free, but this is not always the case, and some allergic individuals must avoid soybean oil and products made with soybean oil (margarine and products made with margarine, salad dressings, and baby foods). The presence of the following terms on the product label may also indicate the presence of soy protein:

\begin{tabular}{|l|l|}
\hline Bulking agent & Miso* \\
\hline Carob & Monosodium glutamate (MSG) \\
\hline $\begin{array}{l}\text { Hydrolyzed vegetable protein (HVP)/ } \\
\text { Hydrolyzed soy protein }\end{array}$ & Protein \\
\hline Lecithin & Starch \\
\hline Artificial and natural flavoring & Textured vegetable protein (TVP) \\
\hline Bulking agent & Vegetable broth/gum/starch \\
\hline \multicolumn{2}{|l}{} \\
*Miso is a paste made from fermented soybeans used as a flavoring agent in Japanese \\
cuisine.
\end{tabular}

Types of foods that are likely to contain soy protein include:

\begin{tabular}{|l|l|}
\hline Baked goods & Asian foods \\
\hline Some breakfast cereals & Processed meats \\
\hline Hamburger patties & Ice cream \\
\hline Butter substitutes/shortening & Liquid/powdered meal replacers \\
\hline Chocolates/candy & Seasoning sauces \\
\hline Canned meat/fish in sauces & Seasoned salt \\
\hline Canned/packaged soups & Snack bars \\
\hline Canned tuna & Bouillon cubes \\
\hline Crackers & TV dinners \\
\hline Gravies/mixes & Tamari* \\
\hline \multicolumn{2}{|l}{} \\
$*$ Tamari is a dark sauce that is similar to but thicker than soy sauce. \\
\hline
\end{tabular}




\section{Peanuts and Tree Nuts}

Peanuts are one of the most severely allergenic foods available in the marketplace. Peanuts are frequently used as a flavoring/seasoning agent in a variety of products. Peanuts and peanut oil are commonly used in Asian cooking as well as other types of cooking. As with soy oil, peanut oil (occasionally referred to as arachis oil) may very well contain an amount of peanut protein sufficient to elicit an allergic reaction. The terms peanut, peanut butter, ground-nut, flavoring, extract, and oriental sauce on a product label generally indicate the presence of peanut protein.

Types of foods that may contain peanut protein include:

\begin{tabular}{|l|l|}
\hline Baked goods/mixes & Chili \\
\hline Battered foods & Soups \\
\hline Some breakfast cereals & Marzipan** \\
\hline Cereal-based products & Satay sauce*** \\
\hline Candy/candy bars/sweets (read label) & Milk formula \\
\hline Ice cream & Chinese dishes/egg rolls \\
\hline Margarine/vegetable oil/vegetable fat & Asian dishes (e.g., Thai/Indonesian) \\
\hline Some grain breads & African dishes \\
\hline Snack foods & Energy bars \\
\hline Barbecue/Worcestershire sauce & Meat substitutes \\
\hline Sunflower seeds* & \\
\hline \multicolumn{2}{|l|}{$*$ Sunflower seeds may be processed on equipment shared with peanuts. } \\
** Marzipan is a paste made of almond and sugar, used on pastry or molded into candy. \\
Marzipan might be made with egg white as well. \\
*** Satay sauce is made with peanuts or peanut butter and soy sauce. It might also be \\
made with other allergenic ingredients such as shrimp paste or fish sauce. \\
\hline
\end{tabular}

Individuals with a peanut allergy may or may not be allergic to tree nuts (almonds, cashews, pecans, walnuts, etc.) as well. Individuals with tree-nut allergies should be cautious of the foods listed above as well as the following: mixed nuts, artificial nuts, nut oils, nut pastes, nut butters, nut extracts, salad dressings, and amaretto products.

\section{Fish and Seafood}

The term "seafood" refers to fish and shellfish. Fish is one of the most common causes of allergic reaction in both adult and children. Some species of fish can cause true allergic reactions as demonstrated by increasing production of immunoglobulin IgE in the affected persons. Current research also reveals cross-reactivity among various species of fish. This means that if one person is allergic to one fish species (such as cod), he/she may be allergic to other fish, such as mackerel and herring. However, certain species of fish contain high levels of histidine (an amino acid), which can be converted into histamine by bacteria following improper temperature management. Reactions to histamine can mimic allergic reactions, but are not indicative of a true allergy. 
Types of foods that might contain fish/seafood proteins include:

\begin{tabular}{|l|l|}
\hline Worcestershire/steak sauce & Surimi* \\
\hline Caesar salad dressing & Caponata** \\
\hline Hot dogs/bologna/ham & Marinara sauce \\
\hline Pizza toppings & Vitamin supplements (read label) \\
\hline Fish sauce & Curry paste \\
\hline Fish stock & \\
\hline \multicolumn{2}{|l|}{ * Surimi is a fish protein (most commonly made from pollack) that is marketed as } \\
imitation seafood. Surimi may contain artificial flavor, sweeteners, egg white, starch, and \\
small amounts of real shellfish. \\
$* *$ Caponata is an eggplant relish that can contain anchovies
\end{tabular}

\section{Shellfish}

Shellfish tends to be a more potent allergen among adults. Shellfish include mollusks (e.g., squid, octopus, clams, and scallops) and crustaceans (e.g., crab, lobster, crawfish, and shrimp). Although shellfish might be incorporated into a variety of foods during processing, the product's label generally states this clearly.

Types of foods that might shellfish proteins include:

\begin{tabular}{|l|l|}
\hline Worcestershire/steak sauce & Surimi* \\
\hline Caesar salad dressing & Caponata** \\
\hline Hot dogs/bologna/ham & Marinara sauce \\
\hline Pizza toppings & Vitamin supplements (read label) \\
\hline Fish sauce & Curry paste \\
\hline Fish stock & Chitin or chitosan*** \\
\hline Shrimp paste & Fermented fish stomach \\
\hline Fermented oyster sauce & \\
\hline $\begin{array}{l}* \\
\text { *Surimi is a fish protein (most commonly made from pollack) that is marketed as } \\
\text { imitation seafood. Surimi may contain artificial flavor, sweeteners, egg white, starch, and } \\
\text { small amounts of real shellfish. } \\
* * \text { Caponata is an eggplant relish that can contain anchovies. } \\
* * * \text { Chitin or chitosan is a chemical compound (polysaccharide) derived from crab or } \\
\text { shrimp shells. It is widely used in foods and other products as a coating agent, bulking } \\
\text { agents, or antimicrobial agent. It is often used in making capsules or other drug delivery } \\
\text { systems. }\end{array}$ \\
\hline
\end{tabular}

\section{Food Additives}

Food additives are frequently incorporated into food products during processing. They may be used as product preservatives, flavor enhancers or sweeteners, coloring agents, conditioners, or stabilizers. Over the years, adverse reactions to certain food additives, casually referred to as allergies, have been reported. Most notably, these include: 
- Sulfite-induced asthma

- Monosodium glutamate-induced asthma. or MSG Symptom Complex

- Aspartame-induced hives and/or migraines

- FD\&C Yellow No. 5 (tartrazine)-induced hives and/or asthma

- Reactions to carmine and cochineal.

Reactions to these additives are not immunologically mediated. Rather, reactions to these food additives are considered idiosyncratic (affecting different people in different ways) in that the mechanism of these reactions remains unknown.

\section{Sulfites}

Sulfites are used as a preservative to prevent browning reactions. Although sulfite-induced asthma is well documented, its mechanisms are not well understood by experts. Sulfite-sensitive individuals should avoid foods with the following terms listed on their label: sulfur dioxide, potassium metabisulfite, sodium metabisulfite, potassium bisulfite, sodium bisulfite, and sodium sulfite.

\section{Monosodium glutamate (MSG)}

Glutamate, an amino acid, occurs naturally in many foods, with particularly high levels in dairy products, meat, fish, and some vegetables. Glutamate has a distinct flavor. Monosodium glutamate (MSG) is added to food as a flavor enhancer. MSG Symptom Complex includes headaches, nausea, rapid heartbeat, vomiting, and a tingling/numbness/burning sensation along the back, neck, arms, face, and chest pains. These MSG-induced symptoms tend to occur in sensitive individuals within 1 hour of consuming large amounts ( $\geq 3$ grams) of MSG or consuming MSG in a liquid (e.g., soup). Individuals with asthma may be predisposed to this syndrome, as well as to MSG-induced asthma attacks. Food products containing MSG will list it on the label. However, MSG may be used in restaurants, especially in Asian cooking.

\section{Aspartame}

Aspartame is an artificial sweetener made from two amino acids: phenylalanine and aspartic acid. Aspartame is marketed as a low-calorie sweetener (NutraSweet ${ }^{\mathrm{TM}}$ and Equal ${ }^{\mathrm{TM}}$ are among its popular names). Associations have been reported between aspartame and a list of adverse symptoms, including headaches or migraines, dizziness, rashes, swelling of the lips and/or eyelids, difficulty breathing, rapid heartbeat, and depression. Individuals with mood disorders may be particularly vulnerable to these reactions. Aspartame is listed on the label of food products, beverages, and in medications, where it may also be used as a sweetening agent.

\section{FD\&C Yellow No. 5 (Tartrazine)}

FD\&C Yellow No. 5, or tartrazine, is a dye used as a coloring agent in food processing. Among sensitive individuals, tartrazine appears to be a trigger for asthma, runny nose, and hives. The presence of this dye in a food or drug should be clearly indicated by the terms FD\&C Yellow No. 5, tartrazine, or possibly E102 on the food product label or drug package insert. Individuals who are sensitive to aspirin may be sensitive to tartrazine as well. 


\section{Cross-Contamination of Foods in and Away from the Home}

If you are allergic or live with an allergic individual, then cross-contamination becomes a daily issue. Cross-contamination refers to the situation through which a "safe" food comes in contact with an allergen-even a small amount. At home, this could occur by cutting a peanut butter sandwich on a cutting board. The board is effectively contaminated with enough peanut allergen to elicit a reaction from the next allergic user. In a bakery, this could occur when an employee removes a sugar cookie for an allergic customer with the same tongs that were used to remove a peanut-butter cookie. In a restaurant, this could occur if the steak you ordered is grilled alongside the fish you are allergic to.

\section{To avoid cross-contamination at home:}

- Separate allergenic foods from other foods by storing them in a plastic box or container in the refrigerator or on the pantry shelf.

- Clean all pots, pans, and utensils thoroughly with soap and hot water immediately after contact with an allergen.

- Wash plates and utensils used with allergenic foods separately and with a separate set of washing and drying cloths.

- Do not use wooden bowls or utensils because they absorb contaminants.

- Wash hands after contact with an allergen or wear non-latex food gloves during food preparation.

\section{To avoid cross-contamination in restaurants:}

- Avoid buffet-style dining.

- Avoid stores or cafes where food products are stored in bulk bins.

- Avoid sliced deli meats, because slicers are used with a variety of products.

- Avoid seafood restaurants if you are allergic to any type of seafood.

- Avoid Asian restaurants (Thai, Indonesian) if you have a peanut or soy allergy.

- Tell your server about your allergy.

- Ask about possible hidden ingredients, especially in salad dressings and sauces.

- Ask about other foods being prepared in the kitchen simultaneously.

- Order simple dishes with sauces on the side.

- Carry a Chef Card - a personalized card with simple instructions to the chef and others, describing your allergy, related ingredients, and cross-contamination issues.

- Don't be afraid to leave a restaurant if you don't feel "safe".

Disclaimer: Not all foods and potential allergens have been included in this handout. Check with your physician or specialist to make sure you have a complete, individualized list. If you are in doubt regarding food label information or product ingredients, contact the food manufacturer.

\section{Additional Resources}

AllAllergy (many topics to search and explore): http://www.allallergy.net/index.html

American Academy of Allergy, Asthma, and Immunology: http://www.aaaai.org, 800-822-2762 
American College of Allergy, Asthma, and Immunology: http://www.acaai.org/

American Lung Association /American Thoracic Society: http://www.lungusa.org/, 800-LUNG-USA

Association of Food, Beverage and Consumer Products Companies' testimony on advisory labeling of major food allergens:

http://www.gmabrands.com/news/docs/Testimony.cfm?DocID=816

Asthma and Allergy Foundation of America: http://www.aafa.org/, 800-7-ASTHMA

Extracts for Allergy Testing: (301) 295-8012

FDA Information on Cosmetics: http://www.cfsan.fda.gov/ dms/cos-toc.html, 800-270-8689

FDA Information about Food Allergens:

http://www.cfsan.fda.gov/ dms/wh-alrgy.html

http://www.cfsan.fda.gov/ dms/ffalrgn.html

Fear of Food, an article from Food Product Design:

http://www.foodproductdesign.com/archive/1998/0198PR.html

Food Allergy and Anaphylaxis Network: http://www.foodallergy.org, 800-929-4040

Food Allergy Research and Resource Program: http://www.farrp.org

Institute of Food Technologists Scientific Status Summaries:

http://members.ift.org/IFT/Research/ScientificStatusSummaries/

Medline Plus: http://www.nlm.nih.gov/medlineplus

National Allergy Bureau: http://www.aaaai.org, 800-9-POLLEN

National Eczema Association for Science and Education: http://www.nationaleczema.org/, 800-8187546

National Heart, Lung and Blood Institute, Asthma Information:

http://www.nhlbi.nih.gov/health/public/lung/index.htm, (301) 251-1222

National Institute of Allergy and Infectious Diseases at NIH: http://www.niaid.nih.gov

National Institute of Environmental Health Sciences: http://www.niehs.nih.gov/

National Jewish Medical and Research Center: http://www.njc.org, 800-222-LUNG

Parents of Asthmatic/Allergic Children: (303) 842-7395

USDA National Agricultural Laboratory, Allergies and Food Sensitivities:

http://www.nal.usda.gov/fnic/etext/000004.html\#xtocid238181 


\section{References}

1. HR 3684 IH. Food Allergen Labeling and Consumer Protection Act of 2003.

2. Institute of Food Technologists. Scientific status summary: Seafood allergy and allergens: a review. 1995 October;49(10): 103-116.

3. Sicherer SH, Sampson HA. Prevalence of peanut and tree nut allergy in the United States determined by means of a random digit dial telephone survey: a five-year follow-up study. Journal of Allergy and Clinical Immunology. 2003;112(6): 1203-7.

4. Steinman HA. Hidden allergens in foods. Journal of Allergy and Clinical Immunology. 1996;98(2): 241-250.

5. Taylor SL, Hefle SL. Food allergies and other food sensitivities. Food Technology. 2001;55(9): 68-83.

6. Taylor SL, Stratton JE, Nordlee JA. Histamine poisoning (scombroid fish poisoning): an allergylike intoxication. J Toxicol Clin Toxicol. 1989;27(4-5): 225-240.

7. U.S. Food and Drug Administration. FDA Medical Bulletin. Monosodium Glutamate. 1996; vol 26(1). Available from: http://www.fda.gov/medbull/january96/msg.html

8. U.S. Food and Drug Administration. Food allergies rare but risky. FDA Consumer May 1994. Available from: http://vm.cfsan.fda.gov/ dms/wh-alrg1.html

9. U.S. Food and Drug Administration. When food becomes the enemy. FDA Consumer JulyAugust 2001, revised April 2004. Available from: http://www.fda.gov/fdac/features/2001/401_food.html.

10. Walton RG, Hudak R, Green-Waite RJ. Adverse reactions to aspartame: double-blind challenge in patients from a vulnerable population. Biol Psychiatry. 1993 Jul 1-15;34(1-2): 13-7.

11. William J, Jr. Food allergens: Effectively managing processing risks. Food Protection Trends. 2004;24(1): 20-22. 
12. Hansen TK, Bindslev-Jansen C, Skov PS, and Poulsen LK. Codfish allergy in adults: IgE crossreactivity among fish species. Annals of Allergy, Asthma and Immunology. 1997 Feb; 78(2): 187-194.

13. Chu KH, Wong SH, and Leung PSC. Tropomyosin is the major mollusk allergens: Reverse transcriptase polymerase chain reaction, expression and IgE reactivity. Marine Biotechnology. 2004 September;2(5):4 99-509.

14. Wild LG and Lehrer SB. Fish and shellfish allergy. Current Allergy and Asthma Reports. 2005 January;5(1): 74-79. 